\title{
Penerapan Metode Iterative Pada Perancangan Sistem Pembukuan Penjualan PT. XYZ
}

\author{
Akhsani Taqwiym \\ Sistem Informasi, STMIK GI MDP \\ Jalan Rajawali No. 14, Palembang \\ akhsani.taqwiym@mdp.ac.id
}

\begin{abstract}
Bookkeeping is an activity carried out by entrepreneurs and businesspeople whose purpose is to record, document transaction activities that occur in business and business processes which then from bookkeeping results are one of the factors in decision making. Recording manually for the time being is felt to be ineffective due to the difficulty of finding transaction data, there is the possibility of human error, lack of efficient storage of documentation, and lack of management in the use of time so that interfere with performance in making bookkeeping. The solution to this problem is to change the manual method to computerized. The method used is the iteration method, application design that is designed is a database-based websitebased application. By using the iterative method, the results are in accordance with the needs and the resolution of problems that occur at PT. XYZ The purpose of designing bookkeeping sales is to be a solution to the problems that occur at PT. XYZ, helps in making notes and bookkeeping automatically, helps store data to be more time efficient and neat. The benefit of iterative reengineering is the change of the manual recording system to a new system by not disrupting the system user in carrying out the sales recordkeeping process. One of the advantages of using iterative methods is the shorter operational time and costs incurred in designing small systems when converted into requirements. From the application of the interactive method, it is obtained that the application designed can help in making notes faster and the data will be stored automatically and correctly. Data storage will be entered into books which can then be accessed by leaders and parties who need the information as needed.
\end{abstract}

Keywords- Iterative method, System Design, Sales Bookkeeping

Abstrak - Pembukuan merupakan suatu kegiatan yang dilakukan oleh para wirausaha maupun pembisnis yang bertujuan untuk mencatat, mendokumentasikan transaksi kegiatan yang terjadi didalam proses usaha maupun bisnis yang kemudian dari hasil pembukuan menjadi salah satu faktor dalam pengambilan keputusan. Pencatatan secara manual untuk saat ini dirasakan kurang efektif dikarenakan sulitnya mencari data transaksi, terdapat kemungkinan kesalahan dari manusia, penyimpanan dokumentasi yang kurang efisien, dan kurangnya manajemen dalam pemanfaatan waktu sehingga menggangu kinerja dalam membuat pembukuan. Solusi dari permasalahan ini ialah mengubah metode manual menjadi terkomputerisasi. Adapun metode yang digunakan ialah metode iterasi, perancangan aplikasi yang dirancang adalah aplikasi berbasis website berbasis data base. Dengan menggunakan metode iterative diperoleh hasil yang sesuai dengan kebutuhan dan penyelesaian masalah yang terjadi pada PT. XYZ. Tujuan perancangan pembukuan penjualan adalah agar menjadi pemecahan permasalahan yang terjadi di PT. XYZ, membantu dalam pembuatan nota dan pembukuan secara otomatis, membantu menyimpan data menjadi lebih efisien waktu dan rapi. Manfaat dari rekayasa ulang iterative adalah perubahan sistem pencatatan manual ke sistem yang baru dengan tidak menggangu pengguna sistem dalam melakukan proses pencatatan pembukuan penjualan. Salah satu keunggulan menggunakan metode iterative adalah waktu operasional yang lebih singkat dan biaya yang dikeluarkan dalam merancang sistem kecil apabila diubah menjadi requirement. Dari penerapan metode interativ diperoleh aplikasi yang dirancang dapat membantu dalam pembuatan nota menjadi lebih cepat dan data tersebut akan tersimpan secara otomatis dan dengan benar. Penyimpanan data akan masuk kedalam pembukuan yang kemudian dapat diakses oleh pimpinan dan pihak-pihak yang membutuhkan informasi tersebut sesuai dengan kebutuhan.

Kata Kunci-Metode Iterasi, Perancangan Sistem, Pembukuan Penjualan

\section{PENDAHULUAN}

Dalam tumbuh kembangnya suatu usaha, baik bergerak dalam bidang jasa maupun barang tidak terlepas dari keterkaitannya dengan pembukuan. Pembukuan yang dilakukan oleh pembisnis maupun wirausaha bertujuan untuk mencatat, mendokumentasikan, dan sebagai salah satu faktor penting dalam pengambilan keputusan oleh para pengguna informasi pembukuan tersebut.[1] Seiiring dengan berkembangnya teknologi pencatatan yang dilakukan oleh pengusaha maupun wirausaha, beradaptasi dengan teknologi. Pembukuan dilakukan dengan menggunakan teknologi yang bertujuan agar pencarian data menjadi lebih cepat sehingga dapat mengefisiensikan waktu, penyimpanan dokumen menjadi lebih rapi dan tidak perlu memakan biaya perawat yang lebih besar dibandingkan dengan metode manual. Information and communication technology atau biasa dikenal dengan sebutan ICT adalah suatu hal yang telah menjadi kebutuhan dimasa sekarang terutama dalam hal pengembangan bisnis.[2]

PT. XYZ merupakan perusahaan yang bergerak dibidang perjalanan agensi yang melayani tiket akomodasi liburan 
seperti tiket pesawat, kereta api, kapal pesiar, atraksi hiburan, kupon hotel serta paket wisata domestik dan internasional. Dalam proses bisnis yang saat ini berjalan pada PT. XYZ, perusahaan menyediakan jasa penjualan tiket yang pada prosesnya pelanggan bisa datang langsung ke kantor atau telepon untuk memesan tiket pesawat kepada bagian penjualan. Pada saat terjadi komunikasi pelanggan akan dilayani oleh bagian penjualan. Bagian penjualan akan melihat dan memberikan pelanggan informasi mengenai harga dan jadwal yang tersedia berdasarkan sistem yang dapat diakses oleh bagian penjualan. Jika pelanggan menyetujui, dilanjutkan dengan terjadinya transaksi. Transaksi yang terjadi akan dibuktikan dengan adanya bukti pembayaran yang berupa nota, didalam nota ini tersedia data pelanggan dan pemesanan seperti nama pelanggan, detail pemesanan, serta kontak pelanggan. Kemudian nota tersebut oleh bagian Administrasi dijadikan dasar pencatatan pada rekapan harian penjualan yang bertujuan untuk mendokumentasikan kegiatan transaksi yang terjadi pada hari ini.[3] Permasalahan yang terjadi di PT. $\mathrm{XYZ}$, dari proses membuat nota sampai dengan membuat pembukuan penjualan yang masih manual sangat tidak efisien dalam segi waktu dan resiko kesalahan yang cukup besar. Misal dalam tiket pesawat terkadang ada pelanggan yang ingin mengubah jadwal penerbangannya, lalu bagian penjualan akan menghubungi ke bagian administrasi untuk mencari detail pemesanan pelanggan tersebut. Hal ini dibutuhkan waktu apalagi jika ada kesalahan penulisan nama ataupun lainnya akan membuang waktu lebih lama lagi.

Untuk menyelesaikan permasalahan yang ada pada PT. XYZ maka perlu adanya perancangan sistem pembuatan nota dan pembukuan penjualan yang terorganisir agar proses kerja dapat lebih efisien. Perancangan sistem adalah merancang atau mendesain suatu sistem yang baik dimulai dari langkah-langkah operasi dalam proses pengolahan data dan proses prosedur-prosedur untuk mendukung operasi sistem.[4] Penelitian ini mengadopsi rekayasa perangkat lunak model iterative. Model iterative adalah proses pengembangan berulang (iterative) atau proses pengembangan bertambah (incremental). [5] Tujuan menerapkan model iterative pada perancangan sistem pembukuan penjualan adalah merancang ulang proses rekayasa perangkat lunak ada domain aplikasi sistem pembukuan penjualan. Proses rekayasa ulang ini dilakukan secara iterative, bertahap dengan sedikit fungsi atau prosedur pada setiap waktunya dan sesingkat mungkin. Sedangkan manfaat dari rekayasa ulang iterative adalah perubahan sistem pencatatan manual ke sistem yang baru dengan tidak menggangu pengguna sistem dalam melakukan proses pencatatan pembukuan penjualan. Salah satu keunggulan menggunakan metode iterative adalah waktu operasional yang lebih singkat dan biaya yang dikeluarkan dalam merancang sistem kecil apabila diubah menjadi requirement. Metode ini mensyaratkan penyelesaian perencanaan, analisis, perancangan atau desain, dan implementasi secukupnya karena digunakan untuk mengembangkan satu bagian dari sistem baru. Perulangan pada metode ini berlanjut sampai semua bagian keseluruhan sistem telah dikembangkan. Metode iterative merupakan metode yang berbasiskan terhadap aplikasi dari Langkahlangkah sederhana yang diulang kedalam sebuah sistem dengan tujuan mencapai solusi dari persamaan tersebut.
Perancangan adalah tahap penerjemahan dari keperluan atau data yang telah dianalisis ke dalam bentuk yang mudah dimengerti oleh pemakai untuk memberikan gambaran secara umum kepada manusia atau penguna tentang sistem yang diusulkan.[6] Perancangan sistem pembuatan nota dan pembukuan penjualan menggunakan metode iteratif dan berbasis website.[7] Perancangan sistem ini akan membuat nota dengan sistematis yang dapat dicetak, didukung oleh fitur pencarian, melakukan proses penyimpanan data nota menjadi lebih cepat dan efisien, dan dapat mengatasi redudansi data. Dengan adanya hasil dari penerapan metode iterative pada analisis kebutuhan sistem pembukuan penjualan akan menghasilkan perancangan sistem pembukuan yang akan menyelesaikan permasalahan yang terjadi pada PT. XYZ.

\section{BAHAN DAN METODE}

\section{A. Kerangka Pemikiran}

Untuk memperoleh data dan keseuaian pada perancangan pembukuan penjualan kerangka pemikiran digambarkan seperti gambar 1. Kerangka pemikiran.

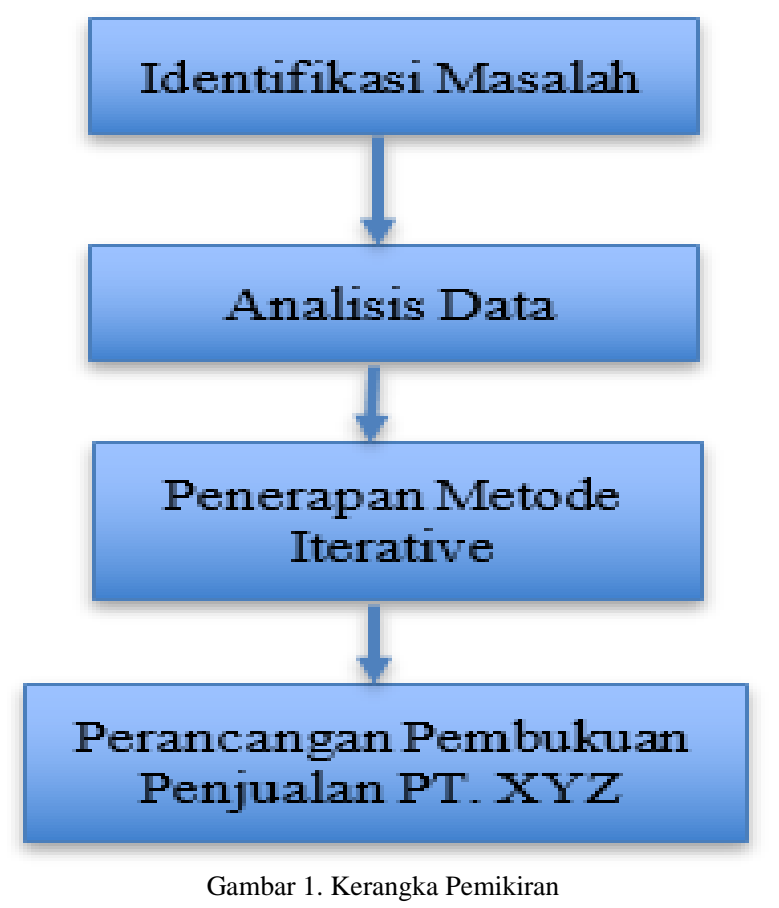

\section{B. Alat Penelitian}

Database adalah sekumpulan data dan informasi yang tersimpan secara sistematik yang dapat diperiksa, diolah atau dimanipulasi dengan menggunakan komputer untuk mendapatkan informasi dari basis data proses yang sedang berjalan.[8] Hasil dari proses analisis proses kerja yang sedang berjalan kemudian dirancang menjadi sebuah sistem baru berupa perancangan aplikasi. 


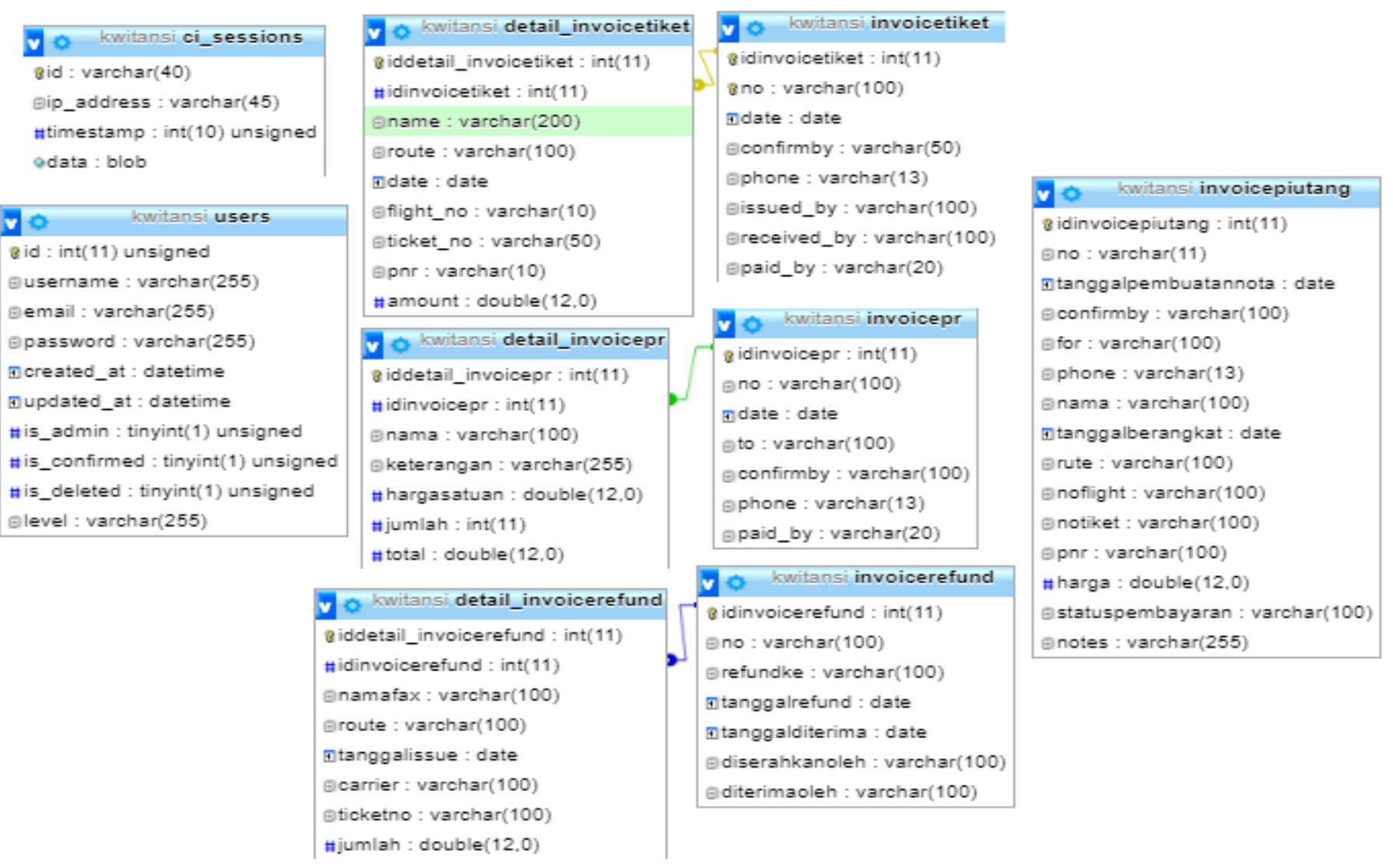

Gambar 2. Database Diagram

\section{Metode Penelitian}

Penelitian menggunakan data tentang proses dan prosedur pencatatan dokumentasi nota transaksi. Dari data tersebut kemudian mendesain perangkat lunak yang selanjutnya digunakan sebagai acuan dalam proses pembuatan invoice tiket, membuat invoice $\mathrm{PR}$, membuat Invoice refund, pembukuan piutang yang kemudian disebut pembukuan tiket, pebukuan PR, dan Pembukuan Refund. Untuk itu dilakukan langkah-langkah penelitian sebagai berikut:

- Mengidentifikasi masalah dan mempelajari proses bisnis yang berjalan pada PT. XYZ

- Mengumpulkan dokumen yang diperlukan dan melakukan perancangan sistem. Analisis sistem yang dimodelkan kedalam suatu bentuk rancangan sistem.

- Membuat kesimpulan penelitian untuk mencapai solusi dan diharapkan diperoleh kesimpulan yang akan memenuhi tujuan penelitian.

Teknik pengumpulan data yang digunakan dalam penelitian ini ialah wawancara secara intensif. Wawancara dilakukan dengan mengajukan beberapa pertanyaan kepada bagian administrasi dan bagian penjualan.[10] Hal ini ditujukan untuk mendapatkan gambaran secara detail mengenai proses yang sedang berjalan dan kekurangan serta kendala yang dihadapi oleh bagian administrasi dan bagian penjualan. Hal ini bertujuan, agar perancangan sistem menjadi lebih baik dan dapat menyelesaikan permasalahan sesuai dengan kendala dan keadaan yang permasalahan yang terstruktur maupun tidak terstruktur. [11]

Metode iterative merupakan pengembangan sistem yang dilakukan secara bertahap sehingga mencapai hasil yang diinginkan.[12] Adapun metode iterative terlihat pada gambar 3. Pemodelan metode iterative

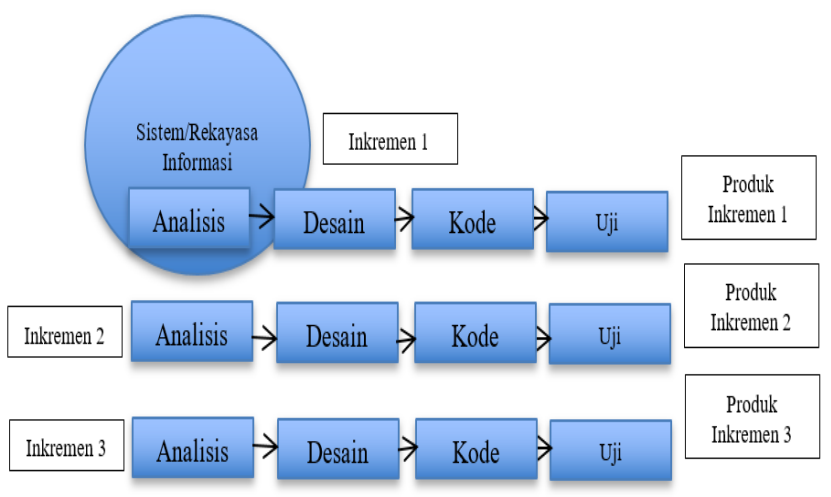

Gambar 3. Pemodelan Metode Iterasi

Gambar 3 adalah bagan metode iterative yang merupakan metode pengembangan sistem yang digunakan pada penelitian ini. 
Adapun pengembangan tersebut dijabarkan, sebagai berikut:

1) Tahap Analisis

Pada tahap ini dilakukan pendefinisian masalah dan penetapan ruang lingkup aplikasi yang akan dibangun. Pengumpulan data dilakukan dengan wawancara secara intensif.[13] Hasil Pengamatan permasalahan yang terjadi pada PT. XYZ diantaranya: Pembuatan nota dan pembukuan yang berlangsung di PT. XYZ mengalami resiko seperti kesalahan menginput data, Proses yang dilakukan secara manual tidak efisien dikarenakan memakan waktu yang cukup lama akibatnya proses kerja PT. XYZ menjadi terhambat. Analisis Kebutuhan yang diperoleh dari analisis yang terjadi pada PT XYZ diantaranya: Nota yang dibuat dengan sistem yang dapat dicetak dan disimpan datanya dengan benar dan Penyimpanan data akan masuk ke dalam pembukuan secara otomatis yang dapat diakses oleh pimpinan. Adapun hasil analisis tergambar pada activity diagram. Activity Diagram adalah alur kegiatan sebuah menu pada sistem yang ada dimana setiap kegiatan rancangan antar muka tampilan pada perangkat lunak. Berikut perancangan activity diagram pada perancangan aplikasi pembuatan nota dan pembukuan PT. XYZ.

\section{a) Activity Diagram Login}

Activity diagram login menjelaskan pengunaan dan sistem yang saling berinteraksi pada form login dimulai dari user membuka website pada browser. Kemudian sistem akan menampilkan form login, pada tampilan ini user diminta memasukkan data pada form login yang bertujuan untuk memastikan user memiliki hak akses aplikasi dan login merupakan salah satu sistem keamanan pada aplikasi. User yang memasukkan data, kemudian sistem akan melakukan pengecekan data dengan menampikan pesan tidak valid jika data salah namun jika pada saat login, berhasil maka user akan masuk ke form selanjutnya. Activity Diagram Login tergambar pada gambar 4. Activity Diagram Login.

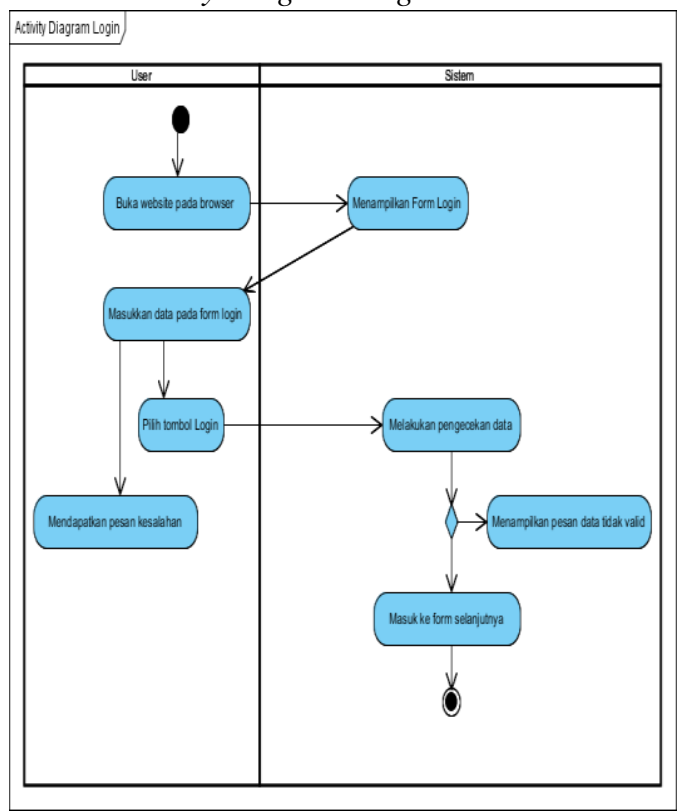

Gambar 4. Activity Diagram Login

\section{b) Activity Diagram Register}

Acrivity diagram register menjelaskan user yang telah mengakses website namun tidak mendapatkan hak akses masuk kedalam sistem maka diharuskan registrasi terlebih dahulu pada bagian ini sistem akan menampilkan form login jika user menekan tombol register kemudian sistem akan menampilkan form register, user dapat melakukan pengisian pada form register jika telah selesai pilih tombol daftar sekarang. Jika semua data lengkap sesuai dengan permintaan pada sistem maka sistem akan menampilkan pesan bahwa pendaftaran sukses dan beralih ke halaman login. Activity Diagram Register tergambar pada gambar 5. Activity Diagram Register.

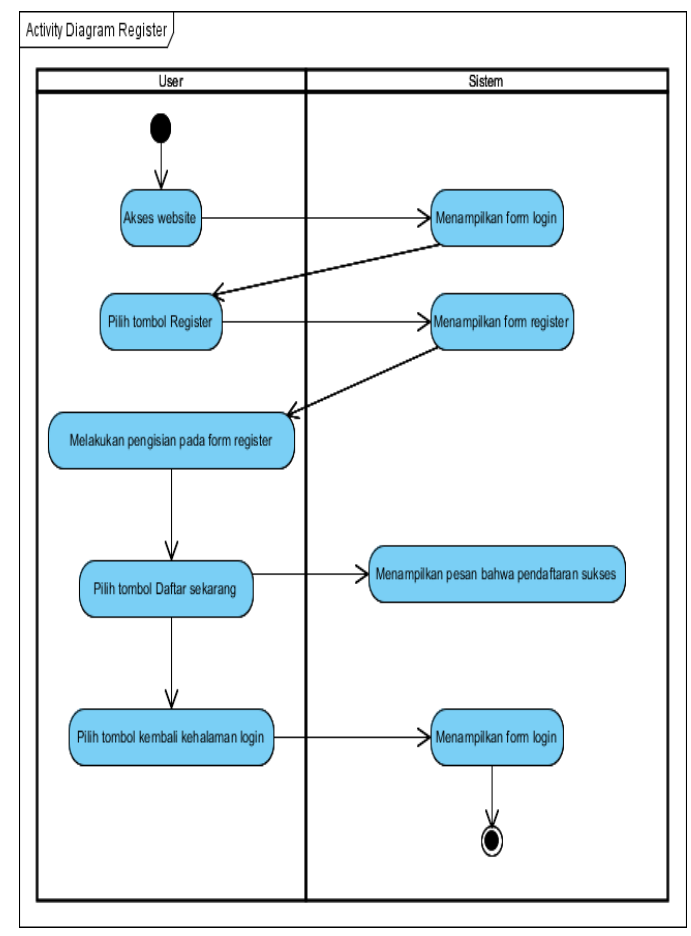

Gambar 5. Activity Diagram Register

\section{c) Activity Diagram Invoice Tiket}

Activity diagram invoice tiket menjelaskan user yang telah memilih form invoice tiket dapat melakukan pengisian form invoice tiket dan memilih tombol simpan jika telah selesai memilih, sistem akan menampilkan nota invoice tiket yang memberikan informasi pemesanan tiket yang telah dilakukan oleh user. Activity Diagram Invoice Tiket tergambar pada gambar 6. Activity Diagram Invoice Tiket 


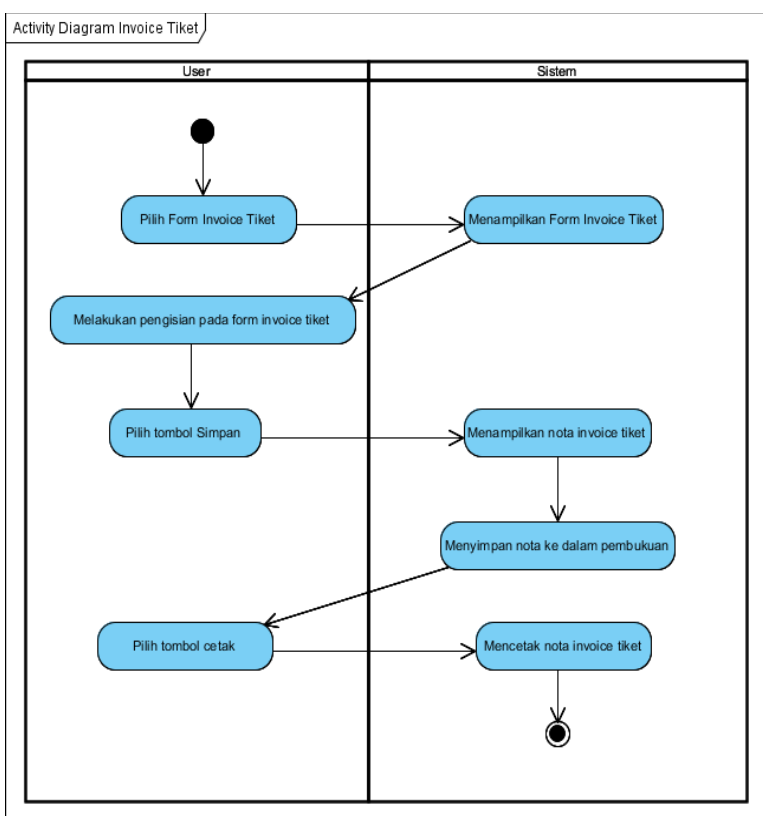

Gambar 6. Activity Diagram Invoice Tiket

\section{d) Activity Diagram Invoice PR}

Activity ini menjelaskan tentang pengguna yang membuat nota penjualan kupon hotel, tiket kapal pesiar, tiket akrtaksi hiburan serta paket wisata domestic dan internasional. Activity Diagram Invoice PR tergambar pada gambar 7. Activity Diagram Invoice PR

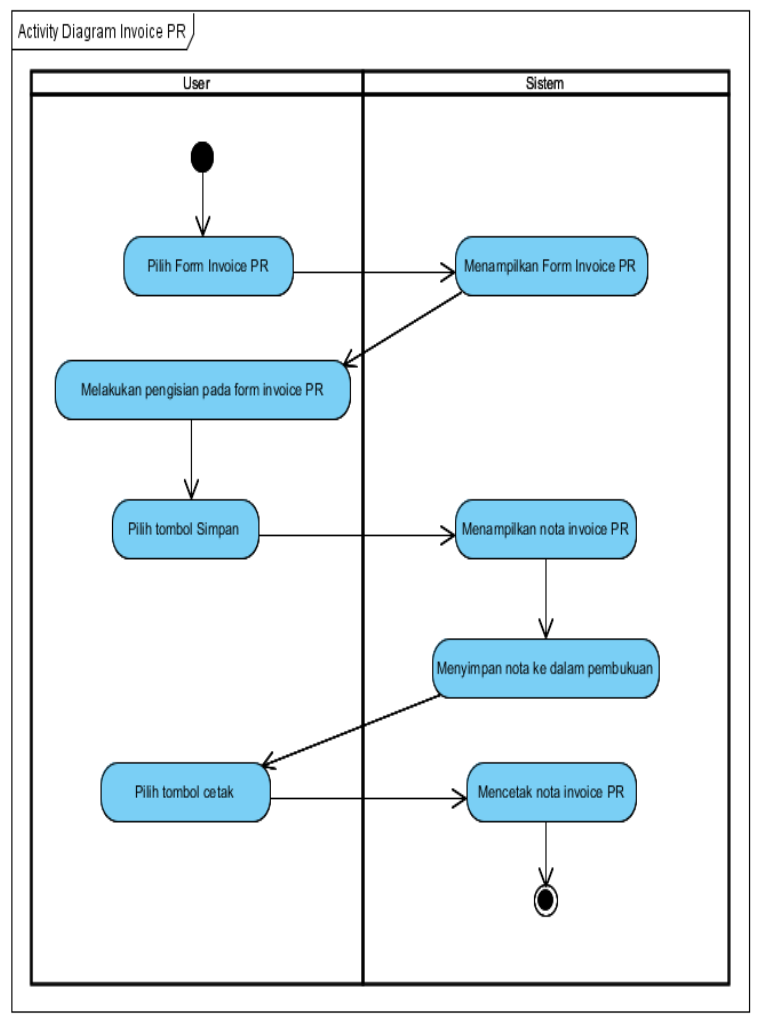

Gambar 7. Activity Diagram Invoice PR e) Activity Diagram Invoice Refund

Activity ini menjelaskan tentang pengguna yang membuat nota pembatalan tiket pesawat. Activity Diagram Invoice Refund tergambar pada gambar 8. Activity Diagram Invoice Refund.

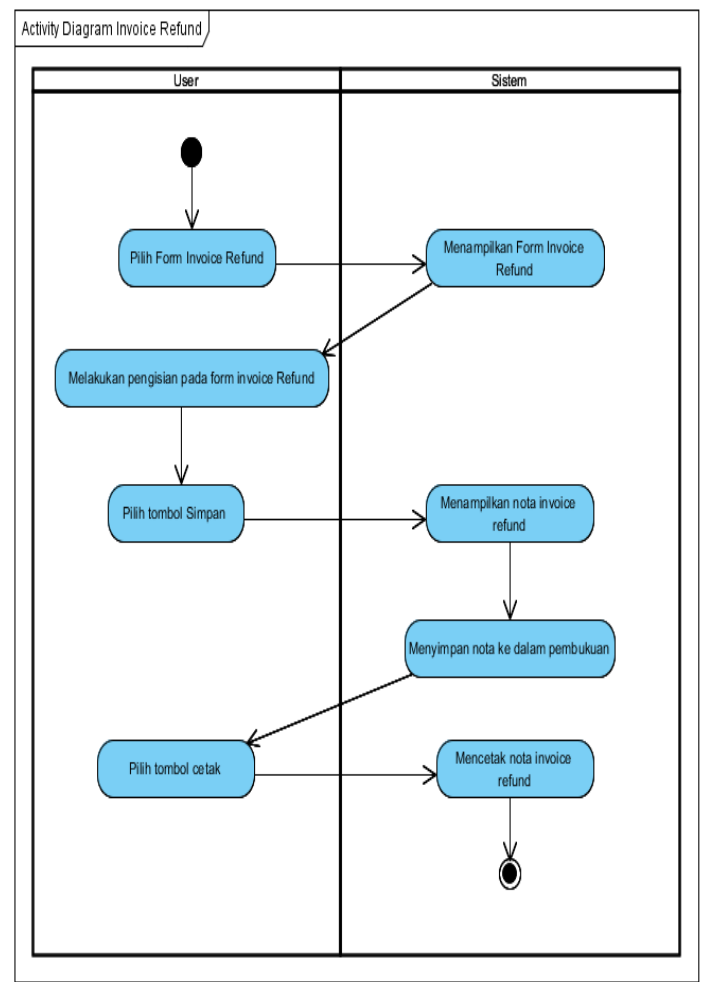

Gambar 8. Activity Diagram Invoice Refund

\section{f) Activity Diagram Pembukuan}

Activity ini menjelaskan mengenai proses untuk melihat dan mencetak pembukuan. Activity Diagram Pembukuan Tergambar pada gambar 9. Activity Diagram Invoice Pembukuan.

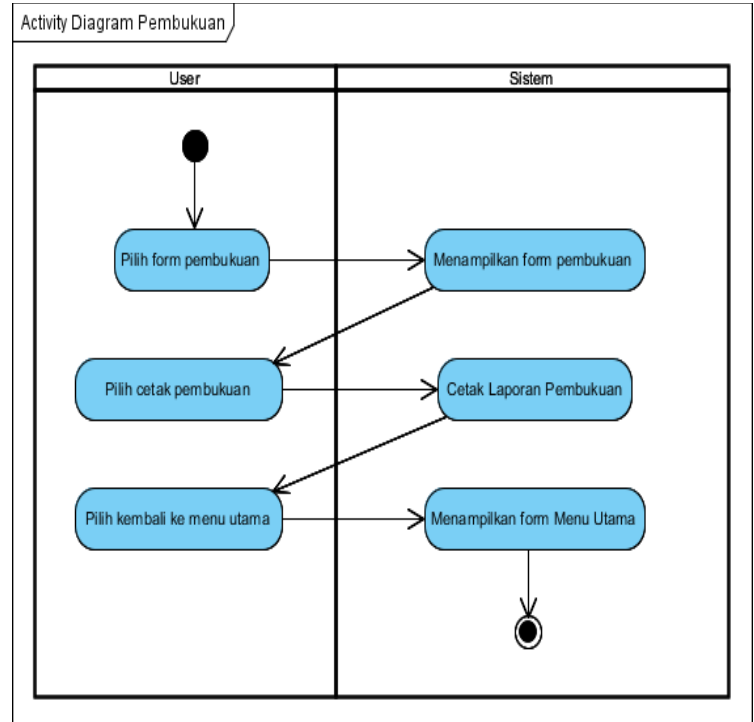

Gambar 9. Activity Diagram Invoice Pembukuan 


\section{2) Tahap Desain}

Pada tahap ini pengembang membuat rancangan aplikasi dengan merancang fitur-fitur utama dan pendukung yang sesuai dengan kebutuhan.[14] Fase inimembantu memberikan gambaran apa yang seharusnya dilakukan pengembang pada tahap selanjutnya. Class Diagram kumpulan objek yang menggambarkan struktur dan deskripsi serta hubungan satu sama lain. Class Diagram tergambar pada gambar 10. Class diagram pada perancangan aplikasi pembuatan nota dan pembukuan.

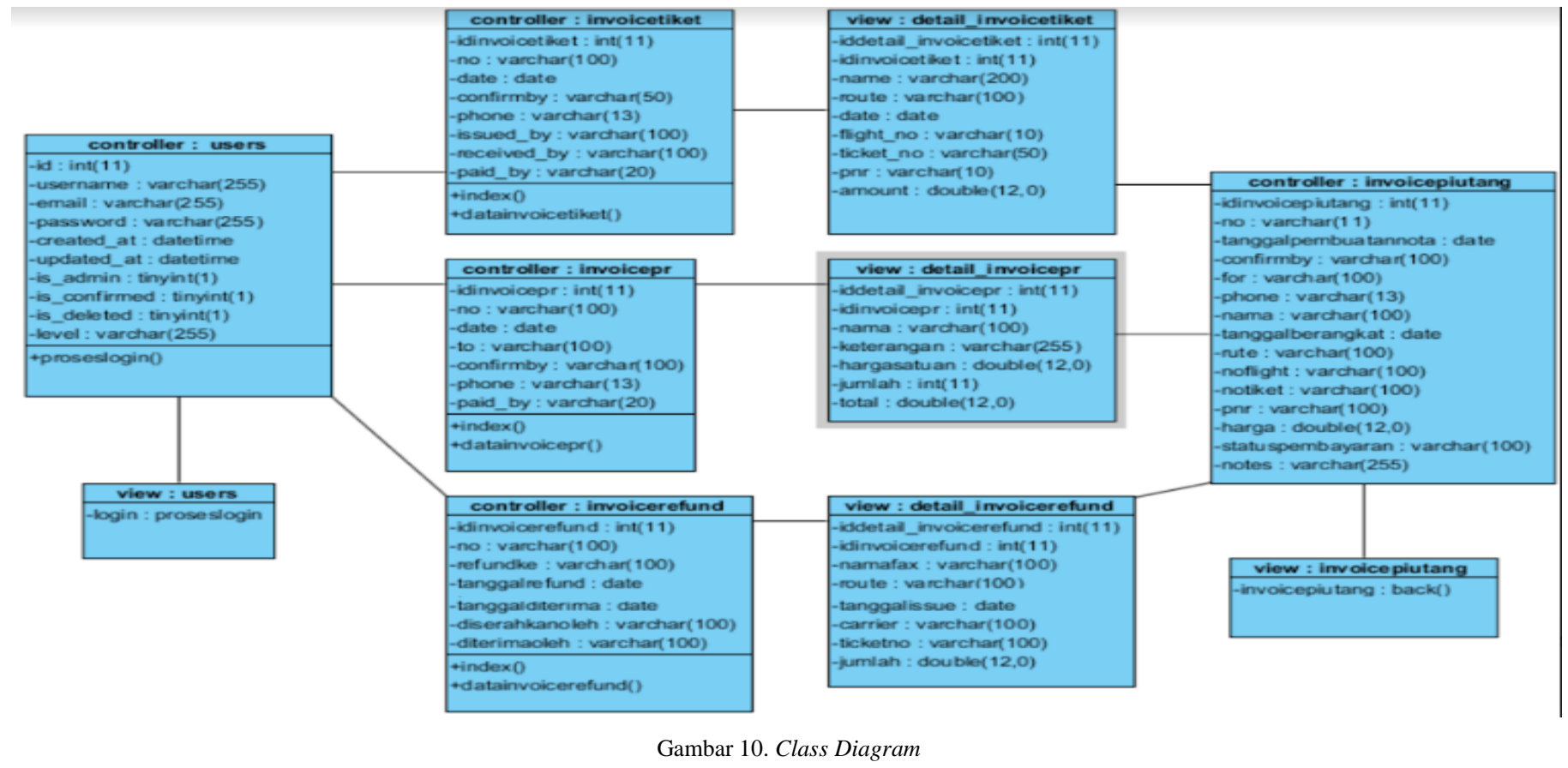

3) Tahap Pembuatan Kode Program

Pada tahap ini desain yang telah dibuat pada fase sebelumnya ditranslasikan ke bentuk program aplikasi. Aplikasi yang dihasilkan pada fase ini haruslah sesuai dengan analisis dan desain yang telah dibuat sebelumnya. Dalam tahap pembuatan kode program yang digunakan adalah notepad++, PHP, MySQL, CodeIgniter, dan Sequence. Diagram.[15]

\section{4) Tahap Pengujian}

Pada tahap ini, pengembang melakukan pengujian pada komponen-komponen aplikasi yang dibangun. Pengujian dilakukan guna memastikan kesesuaian antara logika yang digunakan dan fungsi yang diinginkan pada fitur-fitur aplikasi.

\section{HASIL DAN PEMBAHASAN}

\section{A. Analisa Sistem}

Dalam proses analisis perancangan sistem pembukuan penjualan pada PT. XYZ terdapat pemisahan sistem menjadi beberapa sub komponen yang saling berdiri sendiri, sehingga proses rekayasa ulang pada suatu komponen tidak akan tergantung pada komponen lain. Pemisahan berfungsi untuk menentukan komponen yang akan direkayasa terlebih dahulu sehingga meminimalisir waktu pembekuan dari komponen tersebut. Untuk menentukan apakah komponen layak atau tidak menjadi sebuah komponen, secara umum digunakan rumus MTMR (mean time to maintance request).

$$
\operatorname{MTMR}_{i}=\sum_{j=1}^{n_{i}} \frac{\Delta t_{j . i}}{n_{i}}
$$

MTMRi merupakan waktu rata-rata akses data setiap komponen sistem melakukan proses. Perkiraan waktu merekayasa ulang suatu komponen lebih RTi lebih dari MTMRi maka perlu adanya pemecahan menjadi komponen yang lebih kecil. Hal ini digunakan sebaga acuan untuk meminimalisir waktu pembekuan komponen. Dalam perancangan sistem pembukuan penjualan PT.XYZ tidak diperlukan dikarenakan tidaka da permintaan perubahan fungsionalitas, hanya diperlukan perubahan platform dari proses yang sedang berjalan menjadi proses secara komputerisasi. Dalam penerapan metode iterative pada perancangan sistem pembukuan penjualan di PT. XYZ diperoleh data yang bersifat esensial maupun residual.

\section{B. Klarifikasi Data}

Tahap klasifikasi data merupakan proses pengklasifikasian basis data perancangan sistem pembukuan penjualan. Proses klasifikasi data ini dibatasi hanya pada data yang berhubungan dengan proses Login, pemesanan tiket, pengembalian tiket, dan pembukuan penjualan. Data residual yang terdapat dalam entitas yang berhubungan dengan proses Login, pemesanan tiket, pengembalian tiket, dan pembukuan penjualan 
tergambar pada Tabel 1. Data redundan yang ada di Basisdata.

TABEL 1. DATA REDUNDAN YANG ADA DI BASIS

\begin{tabular}{|c|c|c|c|}
\hline Tabel & Kolom & $\begin{array}{l}\text { Fungsi yang } \\
\text { berhubungan }\end{array}$ & Jenis data \\
\hline Pelanggan & $\begin{array}{l}\text { Kwitansi } \\
\text { ci_sessions }\end{array}$ & Update transaksi & $\begin{array}{l}\text { Data } \\
\text { Redundan } \\
\text { komputasi }\end{array}$ \\
\hline Pelanggan & $\begin{array}{l}\text { Kwitansiinvoic } \\
\text { etiket }\end{array}$ & $\begin{array}{l}\text { Update } \\
\text { pemberitahuan } \\
\text { informasi tiket }\end{array}$ & $\begin{array}{l}\text { Data } \\
\text { Redundan } \\
\text { komputasi }\end{array}$ \\
\hline Pelanggan & $\begin{array}{l}\text { Kwitansi } \\
\text { invoicePR }\end{array}$ & Update invoicePR & $\begin{array}{l}\text { Data } \\
\text { Redundan } \\
\text { komputasi }\end{array}$ \\
\hline Pelanggan & $\begin{array}{l}\text { Kwitansi } \\
\text { invoicerefund }\end{array}$ & $\begin{array}{l}\text { Update } \\
\text { invoicerefund }\end{array}$ & $\begin{array}{l}\text { Data } \\
\text { Redundan } \\
\text { komputasi }\end{array}$ \\
\hline Penjualan & Kwitansi user & Update transaksi & $\begin{array}{l}\text { Data } \\
\text { Redundan } \\
\text { komputasi }\end{array}$ \\
\hline Penjualan & $\begin{array}{l}\text { Kwitansidetail } \\
\text { invoicetiket }\end{array}$ & $\begin{array}{l}\text { Update } \\
\text { pemberitahuan } \\
\text { informasi tiket }\end{array}$ & $\begin{array}{l}\text { Data } \\
\text { Redundan } \\
\text { komputasi }\end{array}$ \\
\hline Penjualan & $\begin{array}{l}\text { Kwitansi detail } \\
\text { invoicePR }\end{array}$ & Update invoicePR & $\begin{array}{l}\text { Data } \\
\text { Redundan } \\
\text { komputasi } \\
\end{array}$ \\
\hline Penjualan & $\begin{array}{l}\text { Kwitansi detail } \\
\text { invoicerefund }\end{array}$ & $\begin{array}{l}\text { Update } \\
\text { invoicerefund }\end{array}$ & $\begin{array}{l}\text { Data } \\
\text { Redundan } \\
\text { komputasi }\end{array}$ \\
\hline Keuangan & $\begin{array}{l}\text { Kwitansidetail } \\
\text { invoicetiket }\end{array}$ & $\begin{array}{l}\text { Update } \\
\text { pemberitahuan } \\
\text { informasi tiket }\end{array}$ & $\begin{array}{l}\text { Data } \\
\text { Redundan } \\
\text { komputasi }\end{array}$ \\
\hline Keuangan & $\begin{array}{l}\text { Kwitansidetail } \\
\text { invoicepiutang }\end{array}$ & $\begin{array}{l}\text { Update } \\
\text { pemberitahuan } \\
\text { invoicepiutang }\end{array}$ & $\begin{array}{l}\text { Data } \\
\text { Redundan } \\
\text { komputasi }\end{array}$ \\
\hline
\end{tabular}

\section{Desain Ulang Data}

Dalam fase ini data desain ulang data dilakukan di basis data dengan tujuan mendesain basis data sesuai dengan desain basis data sistem pembukuan penjualan. Namun dalam rekayasa ulang iterative, desain basis data tujuannya dibedakan oleh klasifikasi data primer dan residual saja. Desain hasil rekayasa ulang ini ditambahkan relasi yang memungkinkan konsistensi data di basis data tujuan.

\section{Mengadaptasikan sistem pembukuan penjualan PT. XYZ}

Perancangan sistem pembukuan penjualan PT. XYZ terdapat beberapa fungsi yang dijalankan selama proses sistem berjalan. Agar aplikasi sistem pembukuan penjualan yang mengakses data residual dapat mendapatkan data tanpa mengakses data residual. Fungsi-fungsi tersebut terdapat pada tabel 2. Fungsi sistem pembukuan penjualan.

\section{TABEL 2. FUNGSI SISTEM PEMBUKUAN PENJUALAN}

\begin{tabular}{|c|c|c|}
\hline Nama Fungsi & Fungsi & Tabel yang berhubungan \\
\hline getInvoicetiket() & $\begin{array}{c}\text { Menghasilkan } \\
\text { invoicetiket }\end{array}$ & Kwitansi invoicetiket \\
\hline getInvoicePR() & $\begin{array}{c}\text { Menghasilkan } \\
\text { invoicePR }\end{array}$ & Kwitansi invoicePR \\
\hline getInvoicerefund() & $\begin{array}{c}\text { Menghasilkan } \\
\text { invoicerefund }\end{array}$ & Kwitansi invoicerefund \\
\hline getInvoicetiket() & $\begin{array}{c}\text { Menghasilkan } \\
\text { invoicetiket }\end{array}$ & Kwitansi invoicetiket \\
\hline getInvoicepiutang() & $\begin{array}{c}\text { Menghasilkan } \\
\text { invoicepiutang }\end{array}$ & Kwitansi invoicepiutang \\
\hline
\end{tabular}

\section{E. Perpindahan Data}

Proses pemindahan data dilakukan dengan memnfaatkan fasilitas DTS (Data Transformation Service) pada SQL server. Dalam hal ini pemindahan dilakukan secara sekaligus, karena pada dasarnya pemindagan data tidak mempengaruhi basis data sistem pembukuan penjualan pada proses yang berjalan.

\section{F. Desain Ulang Fungsi}

Dalam proses adaptasi program perancangan ke basis data tujuannya terdapat analisis fungsi pengaksesan data pada sistem pembukuan penjualan. Proses ini mencari manakah program warisan yang berkaitan dengan data yang direkatasa ulang dan mengadaptasikan fungsi baru untuk mengakses basis data tujuan. Dalam pengerjaan desain ulang fungsi ini tiap komponen utama akan dibuatkan dua kelas. Kelas pertama bertanggung jawab atas masalah tampilan dan kelas control yang bertanggung jawab pada masalah fungsional. Dalam perancangan sistem pembukuan penjualan terdapat beberapa proses penting dalam desain ulang fungsi di sistem. Desain fungsi dalam masing-masing proses, sebagai berikut:

\section{1) Data Banker}

Data banker adalah kelas yang dibuat untuk menyediakan akses bagi basis data pada aplikasi yang direkayasa. Aplikasi yang dimaksud dalam hal ini, adalah aplikasi sistem pembukuan penjualan PT. XYZ.

2) Manajemen session

Dalam interaksi antara sistem pembukuan penjualan dan sistem tujuan diperlukan manajemen session yang dibuat oleh dalam perancangan sistem pembukuan penjualan.

3) Desain ulang sistem Login

Pengecekan login dan penyimpanan session untuk dipakai dalam perancangan sistem pembukuan penjualan.

4) Desain Ulang pemesanan tiket

Pembuatan kelas dalam sistem yang baru dengan fungsi berhubungan dengan pelanggan dan admin penjual tiket.

5) Desain ulang pengajuan pengembalian tiket

Pembuatan kelas dalam sistem baru dengan fungsi jika pelanggan akan mengajukan pengembalian tiket maupun pengantian jadwal pada tiket yang berhubungan dengan admin penjual tiket.

6) Desain ulang laporan invoice tiket

Pembuatan kelas dalam sisem baru dengan fungsi berhubungan dengan laporan yang terjadi oleh pengguna dan admin penjual tiket. History data tiket akan tersimpan dan berhubungan dengan bagian pembukuan.

7) Desain ulang laporan invoice $P R$

Pembuatan kelas dalam sistem baru dengan fungsi berhubungan dengan pelanggan dan bagian pembukuan.

8) Desain ulang menu laporan piutang

Pembuatan kelas dalam sistem yang baru dengan fungsi yang berhubungan dengan pembukuan pada PT. XYZ .

\section{G. Pembahasan Hasil Penelitian \\ 1) Desain Form Login}

Pada tampilan form login mengharuskan pengguna memasukkan username dan password terlebih dahulu kedalam aplikasi. Hal ini bertujuan sebagai pengamanan dari aplikasi 
dan memastikan user yang sedang mengakses aplikasi memiliki hak akses untuk mengunakan aplikasi ini. Didalam form login terdapat pilihan register diperuntukkan untuk pengguna yang baru pertama kali menggunakan aplikasi ini. Form login tergambar seperti pada gambar 12. Form Login.
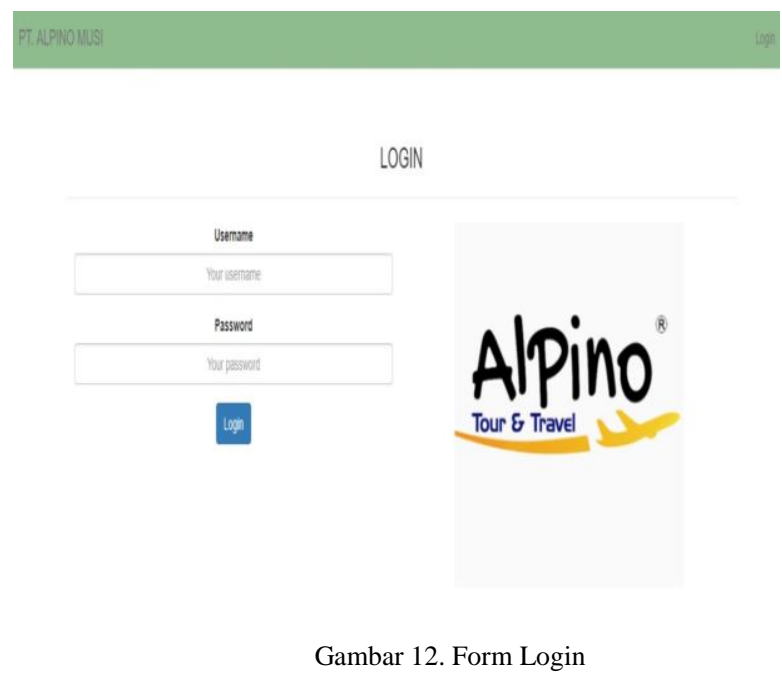

\section{2) Form Register}

Tujuan form register adalah untuk pengguna yang pertama kali menggunakan aplikasi untuk membuat akun agar dapat memiliki hak akses login pada aplikasi. Tampilan form register tergambar pada gambar 13. Form Register.

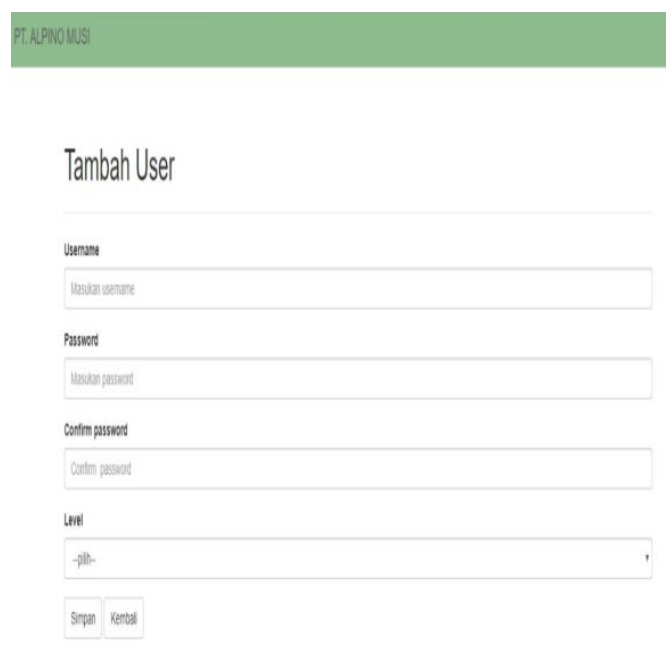

Gambar 13. Form Register

\section{3) Form Menu Utama}

Form menu utama merupakan tampilan halaman depan pada aplikasi yang berisi menu-menu pada aplikasi. Form menu utama tergambar pada gambar 14. Form Menu Utama.

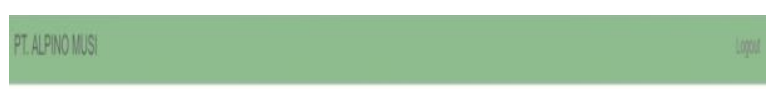

\section{WELCONETOMYAPLLCATION}

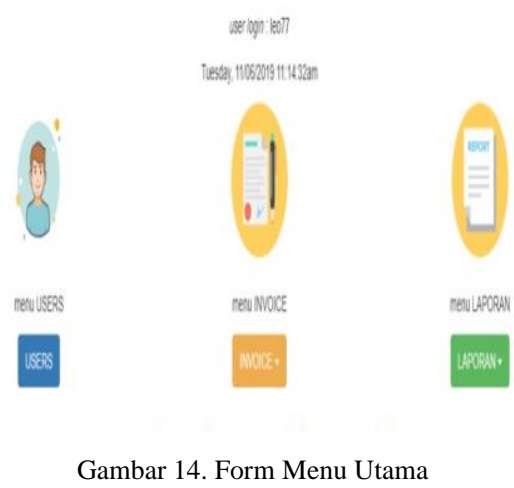

\section{4) Form Menu Invoice Ticket}

Form menu invoice tiket adalah form untuk membuat tiket pesawat, kereta api. Form menu invoice tiket tergambar pada gambar 14. Form Menu Invoice Tiket.

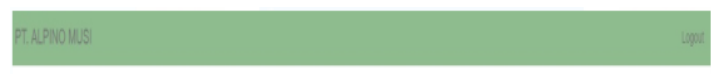

INVOICE TIKET

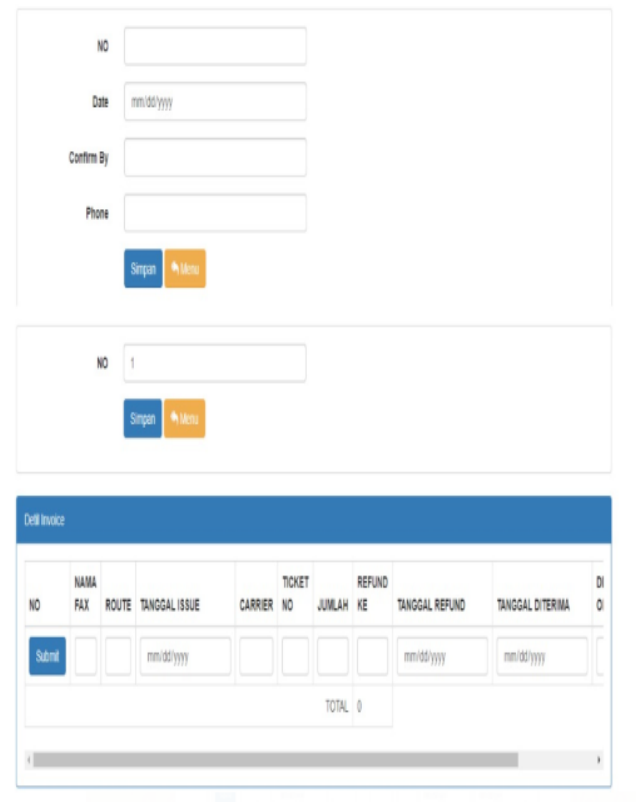

Gambar 15. Form Menu Invoice Tiket

\section{5) Form Menu Invoice Refund}

Form menu invoice refund merupakan form untuk pembatalan nota atau pengembalian dana setelah terjadi transaksi. Form menu invoice refund tergambar pada gambar 


\section{Form Menu Invoice Refund.}

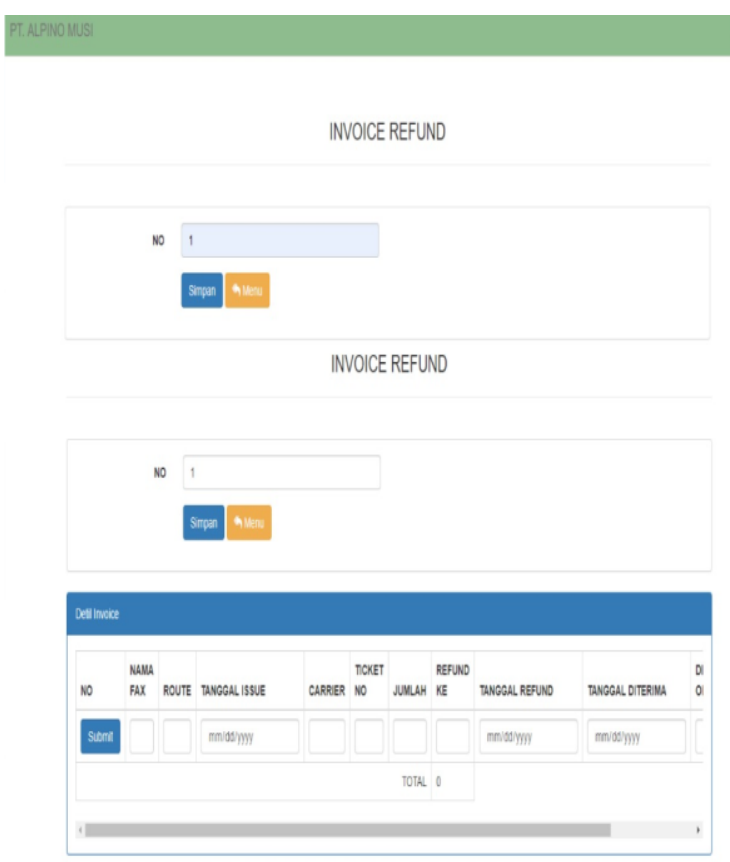

Gambar 16. Form Menu Invoice Refund

\section{6) Pengujian}

Pada tahap pengujian mengunakan pengujian black box pada komponen-komponen yang dibagun. Pengujian black box adalah metode pengujian perangkat lunak yang menguji fungsional aplikasi yang bertentangan dengan struktur internal. Tujuan dalam pengujian pada perancangan sistem pembukuan penjualan adalah memastikan kesesuaian antara logika yang digunakan dan fungsi yang diinginkan fitur-fitur aplikasi digambarkan pada tabel 3 hasil pengujian aplikasi.

TABEL 3. TABEL HASIL PENGUJIAN APLIKASI

\begin{tabular}{|c|l|c|c|}
\hline No & Kasus & Hasil yang diharapkan & $\begin{array}{c}\text { Hasil } \\
\text { pengujian }\end{array}$ \\
\hline 1 & $\begin{array}{l}\text { Menekan } \\
\text { menu login }\end{array}$ & $\begin{array}{c}\text { Menampilkan form login yang berisi } \\
\text { username dan password }\end{array}$ & Berhasil \\
\hline 2 & $\begin{array}{l}\text { Menekan } \\
\text { menu } \\
\text { register }\end{array}$ & $\begin{array}{c}\text { Menampilkan form register yang } \\
\text { berisi usermane, password, confirm } \\
\text { password, dan level }\end{array}$ & Berhasil \\
\hline 3 & $\begin{array}{l}\text { Menekan } \\
\text { menu } \\
\text { utama }\end{array}$ & $\begin{array}{l}\text { Menampilkan form menu utama yang } \\
\text { berisi form invoice tiket, form invoice } \\
\text { refund, form invoice pr, laporan } \\
\text { invoice tiket, laporan invoice refund, } \\
\text { laporan invoice PR dan laporan } \\
\text { piutang }\end{array}$ & Berhasil \\
\hline 4 & $\begin{array}{l}\text { Menekan } \\
\text { menu } \\
\text { invoice } \\
\text { tiket }\end{array}$ & $\begin{array}{l}\text { Menampilkan form invoice tiket dan } \\
\text { ketika menekan pesan, data yang diisi } \\
\text { akan masuk kedalam laporan invoice } \\
\text { tiket }\end{array}$ & Berhasil \\
\hline 5 & $\begin{array}{l}\text { Menekan } \\
\text { menu } \\
\text { invoice } \\
\text { refund }\end{array}$ & $\begin{array}{l}\text { Menampilkan form invoice refund dan } \\
\text { ketika menekan pesan, data yang diisi } \\
\text { akan masuk kedalam laporan invoice } \\
\text { refund }\end{array}$ & Berhasil \\
\hline 6 & $\begin{array}{l}\text { Menekan } \\
\text { menu } \\
\text { invoice PR }\end{array}$ & $\begin{array}{l}\text { Menampilkan form invoice PR dan } \\
\text { ketika menekan pesan, data yang diisi } \\
\text { akan masuk kedalam laporan invoice } \\
\text { PR. }\end{array}$ & Berhasil \\
\hline
\end{tabular}

\begin{tabular}{|c|l|c|c|}
\hline No & Kasus & Hasil yang diharapkan & $\begin{array}{c}\text { Hasil } \\
\text { pengujian }\end{array}$ \\
\hline 7 & $\begin{array}{l}\text { Menekan } \\
\text { menu } \\
\text { laporan } \\
\text { invoice } \\
\text { tiket }\end{array}$ & $\begin{array}{c}\text { Menampilkan form laporan invoice } \\
\text { tiket dan laporan bisa di cetak }\end{array}$ & Berhasil \\
\hline 8 & $\begin{array}{l}\text { Menekan } \\
\text { menu } \\
\text { laporan } \\
\text { invoice } \\
\text { refund }\end{array}$ & $\begin{array}{l}\text { Menampilkan form laporan invoice } \\
\text { refund dan laporan bisa di cetak }\end{array}$ & Berhasil \\
\hline 9 & $\begin{array}{l}\text { Menekan } \\
\text { menu } \\
\text { laporan } \\
\text { invoice PR }\end{array}$ & $\begin{array}{c}\text { Menampilkan form laporan invoice } \\
\text { PR dan langsung bisa di cetak }\end{array}$ & Berhasil \\
\hline 10 & $\begin{array}{l}\text { Menekan } \\
\text { menu } \\
\text { laporan } \\
\text { Piutang }\end{array}$ & $\begin{array}{c}\text { Menampilkan form laporan piutang } \\
\text { dan bisa di print }\end{array}$ & Berhasil \\
\hline
\end{tabular}

\section{KESIMPULAN}

Kesimpulan dari penerapan metode iterative pada perancangan sistem pembukuan penjualan pada PT. XYZ dapat menjadi salah satu alternative pemecahan masalah diantaranya: aplikasi yang dirancang dapat membantu dalam pembuatan nota menjadi lebih cepat dan data tersebut akan tersimpan secara otomatis dan dengan benar. Penyimpanan data akan masuk kedalam pembukuan yang kemudian dapat diakses oleh pimpinan dan pihak-pihak yang membutuhkan informasi tersebut sesuai dengan kebutuhan.

\section{REFERENCES}

[1] B. Derviş, "Perancangan Sistem Informasi Pembukuan Berbasis Website Bagi Ukm Percetakan Di Kota Depok," J. Chem. Inf. Model., vol. 53, no. 9, hal. 1689-1699, 2013, doi: 10.1017/CBO9781107415324.004.

[2] Y. Rahmadi, Y. A. P, dan M. A. H, "Pengembangan Modul Freemium Aplikasi TEL-US (Telkom University Store) menggunakan Metode Iterative Incremental dan Framework Laravel," Pengemb. Modul Free. Apl. Tel-Us (Telkom Univ. Store) Menggunakan Metod. Iterative Increm. Dan Framew. Laravel, vol. 2, no. 2, hal. 5437-5444, 2015.

[3] Z. Z. Tazkia, "Perancangan Sistem Informasi Akuntansi Laporan Keuangan Laba Rugi pada Restoran Eatboss Dengan Menggunakan PHP dan MySQL," is Best [Accounting Inf. Syst. Inf. Technol. Bus. Enterp., vol. 4, no. 1, hal. 426-440, 2019, doi: 10.34010/aisthebest.v4i1.1831.

[4] Akhsani Taqwiym, "Perancangan Aplikasi Promosi Shirouoshien Berbasis Android," Teknomatika, vol. 08, no. 02, hal. 193-204, 2018, doi: ojs.palcomtech.ac.id.

[5] N. Wijaya, "Aplikasi Pengelolaan Data Kepegawaian Berbasis Web Pada Pt. Pelayaran Sakti Inti Makmur Palembang," J. Sisfokom (Sistem Inf. dan Komputer), vol. 9, no. 1, hal. 42-50, 2020, doi: 10.32736/sisfokom.v9i1.706.

[6] R. Rachman Andi, Beny, dan E. Fernando, "Perancangan E-Commerce Berbasis Website Pada Toko Dunia Palembang," J. Ilm. Process., vol. 12, no. 2, hal. 1102-1117, 2017.

[7] D. Zaliluddin dan R. Rohmat, "Perancangan Sistem Informasi Penjualan Berbasis Web (Studi Kasus Pada Newbiestore)," Infotech J., vol. 4, no. 1, hal. 236615, 2018.

[8] S. Surahman dan E. B. Setiawan, "Aplikasi Mobile Driver Online Berbasis Android Untuk Perusahaan Rental Kendaraan," J. Ultim. InfoSys, vol. 8, no. 1, hal. 35-42, 2017, doi: 10.31937/si.v8i1.554.

[9] I. K. Sriwana, M. L. Christia, E. Ellytasia, dan G. Chandiawan, 
"Perancangan Sistem Informasi Inventory Pt. Abc," J. Ilm. Tek. Ind., vol. 6, no. 1, hal. 9-19, 2019, doi: 10.24912/jitiuntar.v6i1.3019.

[10] E. F. Wati dan A. A. Kusumo, "Penerapan Metode Unified Modeling Language ( UML ) Berbasis Desktop Pada Sistem Pengolahan Kas Kecil Studi Kasus Pada PT Indo Mada Yasa Tangerang," J. Inform., vol. 5, no. 1, hal. 24-36, 2016.

[11] H. . Jogiyanto, Analisis dan Desain Sistem Informasi : Pendekatan Terstruktur Teori dan Praktik Aplikasi Bisnis. Yogyakarta: Andi Offset, 2005.

[12] G. P. Ningsi dan S. Mungkasi, "Penerapan Metode Runge-Kutta dan Iterasi Variasional dalam Simulasi Transmisi Tuberkulosis," Limits $J$. Math. Its Appl., vol. 16, no. 2, hal. 147, 2020, doi: 10.12962/limits.v16i2.5818

[13] Jogiyanto, Analisis dan Desain Sistem Informasi. Yogyakarta: Andi Offset, 2005.

[14] R. A. Saputra, L. S. Ramdhani, dan S. Supriatman, "Penerapan Metode Iterative Dichotomizer 3 (Id 3) Untuk Menentukan Beasiswa Berprestasi Pada Smp Pgri Caringin Sukabumi,” J. Pilar Nusa Mandiri, vol. 15, no. 1, hal. 35-40, 2019, doi: 10.33480/pilar.v15i1.29.

[15] H. O. L. Wijaya, "Implementasi Metode Pieces Pada Analisis Website Kantor Penanaman Modal Kota Lubuklinggau," JUSIM (Jurnal Sist. Inf. Musirawas), vol. 3, no. 1, hal. 46-55, 2018, doi: 10.32767/jusim.v3i1.289. 